Article

\title{
Fluorimetric Properties of 3-Aminoflavone Biomolecule (3-AF). X-ray Crystal Structure of New Polymorph of 3-AF
}

\author{
Wojciech Pająk ${ }^{1}$, Małgorzata Fabijańska ${ }^{2, *}$, Jakub Wojciechowski ${ }^{3}$, Wojciech M. Wolf ${ }^{3}$, \\ Anna Kilanowicz ${ }^{4}$, Elżbieta Brzezińska ${ }^{1}$ and Justyn Ochocki ${ }^{2, * \mathbb{D}}$ \\ 1 Department of Analytical Chemistry, 1 Muszyńskiego Str., Medical University of Lodz, 90-151 Lodz, Poland \\ 2 Department of Bioinorganic Chemistry, 1 Muszyńskiego Str., Medical University of Lodz, \\ 90-151 Lodz, Poland \\ 3 Institute of General and Ecological Chemistry, Łódź University of Technology, 116 Żeromskiego St., \\ 90-924 Lodz, Poland \\ 4 Department of Toxicology, 1 Muszyńskiego Str., Medical University of Lodz, 90-151 Lodz, Poland \\ * Correspondence: malgorzata.fabijanska@umed.lodz.pl (M.F.); justyn.ochocki@umed.lodz.pl (J.O.); \\ Tel.: +48(42)-6779220 (J.O.)
}

Academic Editor: Josef Jampilek

Received: 2 July 2019; Accepted: 12 August 2019; Published: 13 August 2019

\begin{abstract}
The crystal structure of the new polymorphic form of 3-aminoflavone (3-AF) has been determined by single crystal $\mathrm{X}$-ray diffraction. This report presents results of fluorimetric studies on 3-AF in methanol and aquatic solvents. Based on 3D fluorescence emission spectra, optimal values for excitation $\left(\lambda_{\mathrm{ex}}\right)$ and emission/analytical $\left(\lambda_{\mathrm{em}}\right)$ wavelength, the analytical concentration range as well as the range of concentration quenching for the studied compound were established. Moreover, the limit of detection (LOD) and the limit of quantification (LOQ) were determined. The results were compared with those obtained using the standard UV-Vis absorption spectrophotometric method. The effect of acidity $(\mathrm{pH})$ and the concentration of halide anions (chlorides, bromides, iodides and fluorides) on fluorescence quenching were analysed.
\end{abstract}

Keywords: 3-aminoflavone; X-ray crystallography; fluorescence; LOD (limit of detection); LOQ (limit of quantification); concentration quenching

\section{Introduction}

Flavonoids belong to a group of plant secondary metabolites that display a wide spectrum of biological activity. Chemically, flavonoids have the general structure of a 15-carbon skeleton, which consists of two phenyl rings and a heterocyclic ring. The compounds are derivatives of benzo- $\gamma$-pyrone. The biological activity, metabolism, chemical and physical properties of flavonoids depend on the kind, number and position of the functional groups attached to the molecule. Natural flavonoids as well as their synthetic derivatives display various pharmacological activities, including anti-oxidative, anti-inflammatory, vasoprotective and anti-proliferative. This class of compounds has been a major object of scientific interest since the discovery of their anti-oxidative activity, i.e., the ability to scavenge free radicals and reactive oxygen species (ROS) [1-5].

Flavonoid derivatives, particularly complexes containing metals, also demonstrate biological and pharmacological properties. Their derivatives that could be applied in antineoplastic chemotherapy are particularly interesting [6]. For this purpose, among others, 3-aminoflavone complexes were synthesized [7-13]. The trans- $\mathrm{Pt}_{2} \mathrm{Cl}_{2}$ complex (referred to as TCAP) is an example of such synthesis. The compound appeared to be cytotoxic for many tested cancer cell lines. Besides that, it proved to be much less toxic for normal lymphocytes in comparison to cisplatinum, which decreases the number of 
potential adverse effects. Therefore, it can be a potential drug in antineoplastic therapy if cisplatinum cannot be administered.

Ruthenium(III) is another metal which forms interesting complexes with 3-aminoflavone. In vitro and in vivo studies revealed good antineoplastic properties of this complex. Some ruthenium complexes, despite their low toxicity, demonstrate effective proapoptotic or antimetastatic properties. Thus, ruthenium complexes with flavonoid compounds could constitute an interesting group of compounds that have potential antineoplastic activity [14].

The ability of flavonoids to coordinate metal ions is also applied in the improvement of preparative and analytical techniques. Because of their structure and electron configuration, a great number of flavonoid compounds display fluorescence after excitation with visible or UV light. The structure of rings with a system of conjugated double bonds and delocalized $\pi$ electrons makes the molecules highly sensitive colorimetric and fluorimetric reagents in analytical chemistry. Chelation of metal ions often affects or quenches the fluorescence in a specific way that can be measured and applied for the quantitative determination of flavonoid-metal complexes $[6,15,16]$. Furthermore, this method could be finally applied to the detection of potential drugs.

M. Rhia L. Stone et al. reported and discussed fluorescent antibiotics as new tools to fight bacteria resistance. Applications of fluorescent antibiotics include: Examining toxicity and mode of action of the drug, detecting the presence of antibiotics and diagnostic imaging of bacterial infection [17].

As a continuation of our study on metal complexes with flavone derivatives, a novel polymorph of 3-aminoflavone (Figure 1) was discovered, and its crystal structure as well as detailed fluorimetric study was described.

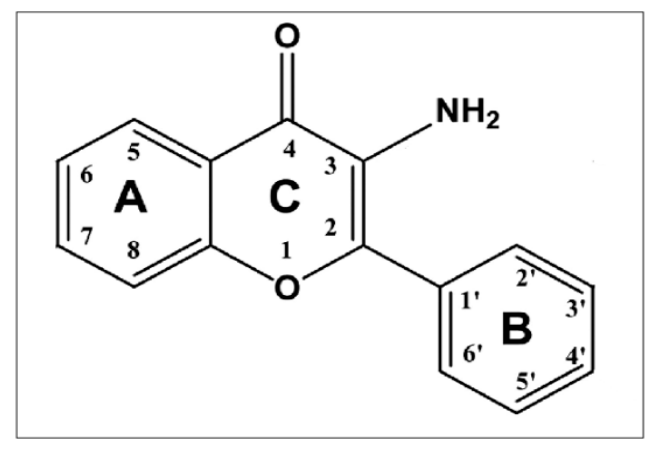

Figure 1. Structural formula of 3-aminoflavone.

\section{Results and Discussion}

\subsection{Crystal Structure Studies}

The molecular structure of a novel orthorhombic polymorph of 3-AF, i.e., 1o, is presented in Figure 2a. Its superposition on the already reported monoclinic structure [13] $1 \mathrm{~m}$ is shown in Figure $2 \mathrm{~b}$. The former crystallizes in a chiral $\mathrm{P} 2{ }_{1} 2_{1} 2_{1}$ space group while crystals of the latter adopt the centrosymmetric $\mathrm{P} 21 / \mathrm{n}$ symmetry. In both structures the benzopyran moieties are practically planar, root mean square (r.m.s.) deviations for 1 o and $1 \mathrm{~m}$ are 0.01 and $0.02 \AA$, respectively. Molecular conformation is restricted by the mutual positions of benzopyran and phenyl fragments and may be conveniently defined by the dihedral angle between both moieties, $\varphi=28.7(4)$ and 40.7(5) ${ }^{\circ}$, as in 10 and $\mathbf{1 m}$, respectively. The exocyclic amine groups adopt diverse configurations in both polymorphs. In 10 the nitrogen atom adopts the tetrahedral $\mathrm{sp}^{3}$ configuration while in $1 \mathbf{m}$ it is planar, indicating the $\mathrm{sp}^{2}$ hybridization. Interestingly, none of the amine hydrogens are involved in the regular intermolecular hydrogen bonds. They form close contacts with the neighboring carbonyl oxygens, which may be regarded as intramolecular hydrogen bonds [O $\cdots \mathrm{N} 2.673(4), 2.684(5) \AA ; \mathrm{O} \cdots \mathrm{H}-\mathrm{N} 114(2), 101(2)^{\circ} ; \mathrm{O} \cdots \mathrm{H}$ 2.21(3), 2.36(2) $\AA$ for 10 and $\mathbf{1 m}$, respectively. Bond lengths are close to those observed in related compounds. The major difference between both polymorphs is related to the exocyclic carbonyl bonds 
conjugated with the endocyclic $\mathrm{C}=\mathrm{C}$ bond. The former is slightly longer in $\mathbf{1 m}$ as compared to that in $10(1.244(3)$ and 1.224(2) $\AA$, respectively), while the latter behaves in the opposite way (1.358(3) and 1.381(2) $\AA$, respectively). This indicates that the following electron delocalization is slightly higher in the reported orthorhombic polymorph 10 than that in monoclinic $\mathbf{1 m}$.

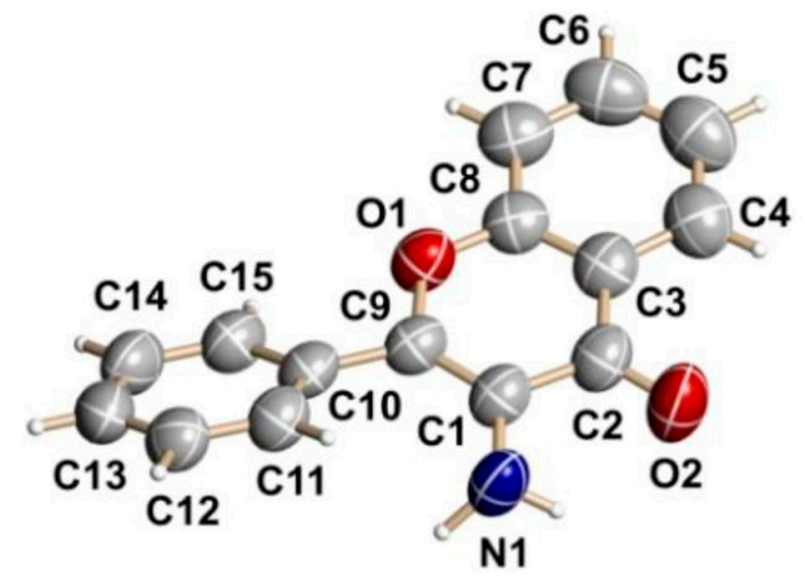

a)

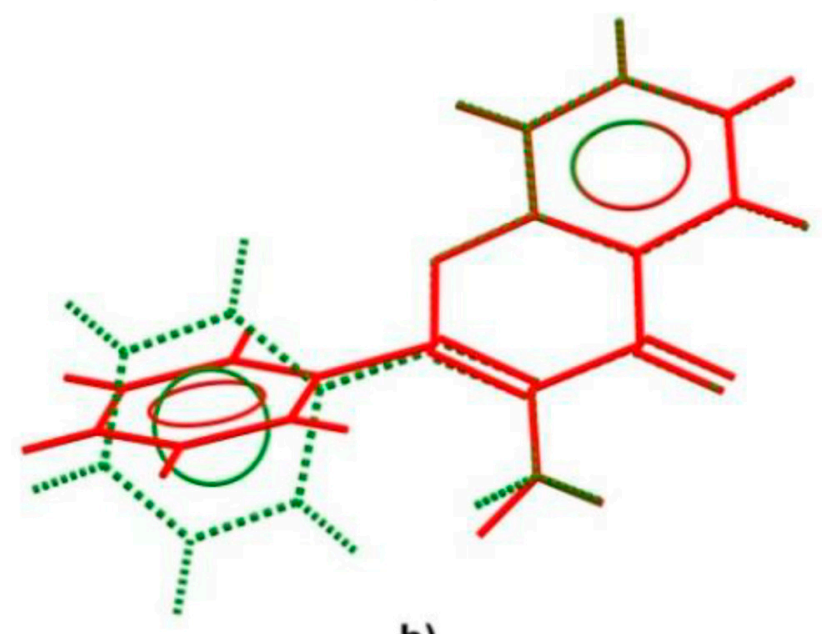

b)

Figure 2. A view of 10 with atom numbering scheme. Displacement ellipsoids for non-hydrogen atoms were draw with 50\% probability level-(a); superposition of 3-AF molecules from crystal 1o (red) and centrosymmetric $1 \mathrm{~m}$ (dashed green)-(b).

A CrystalExplorer program [18] was used to investigate differences in the packing and intermolecular interactions between both polymorphs. Hirshfeld surfaces mapped with electrostatic potential calculated at the B3LYP/6-311++G(d,p) level and fingerprint plots (scattergrams of external (de) and internal (di) contact distance from atoms to Hirshfeld surface) for $\mathbf{1} \mathbf{m}$ and 10 are presented in Figure 3. The main difference is visualized as a negative charge above the amine group in 1o. It can be assigned to a lone pair localized on the $\mathrm{sp}^{3}$ hybridized nitrogen atom.

In both polymorphs, weak intermolecular interaction between amine groups can be observed. In $1 \mathrm{~m}$ it is a short $(1.86(2) \AA) \mathrm{H} \cdots \mathrm{H}$ contact, while in 10 it is a strong contact $\mathrm{H}^{\cdots} \mathrm{N}(2.36(2) \AA$ ). The latter stabilizes infinite chains along the [100] twofold screw axis, which generates a helical arrangement of molecules. The search made with the CCDC Mercury program in CSD version 5.36 revealed 297 identical motifs created by the $-\mathrm{NH}_{2}$ group with the average $\mathrm{N} \cdots \mathrm{H}$ contact distance $2.450 \AA$. Similar weak stacking interactions between benzopyrane moieties can be found in both polymorphs (distances between respective ring centroids are 3.586(2) $\AA$ and 3.661(2) $\AA$ in 1m and 1o, respectively). 

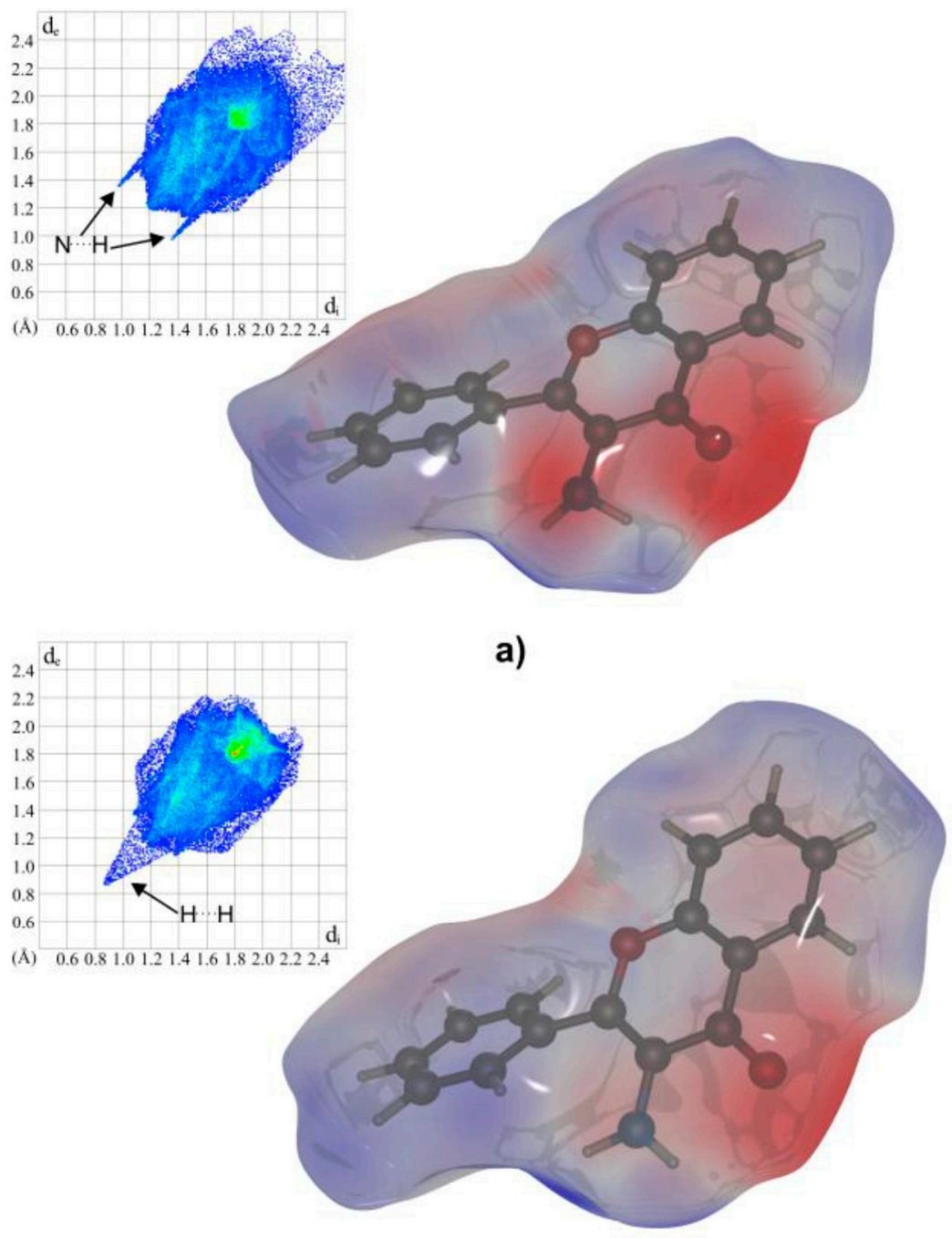

b)

Figure 3. Hirshfeld surfaces mapped with electrostatic potential calculated with B3LYP/6-;311++G(d,p) and the fingerprint plots for $10-(\mathbf{a})$ and $1 \mathbf{m}-(\mathbf{b})$.

\subsection{Electron Absorption Spectra (UV-Vis) of 3-Aminoflavone in Water and Methanol}

In preliminary studies, spectra of 3-AF were recorded in water and methanol. The studies were aimed at estimating the solubility of the compound and checking its stability in solution.

(a) Absorption spectroscopy studies in methanol

It was established by us that the solubility of the studied compound is much better in methanol than in water. Figure 4 presents the UV-Vis spectrum of 3-aminoflavone, at a concentration of $\mathrm{c}=100 \mu \mathrm{g} / \mathrm{mL}$, which corresponds to a molar concentration $\mathrm{c}_{\mathrm{m}}=0.1 \mathrm{~g} / \mathrm{L}(237.252 \mathrm{~g} / \mathrm{mol})=4.215 \cdot 10^{-4} \mathrm{~mol} / \mathrm{L}$.

The observed spectrum has three distinctive bands with maxima at $\lambda=364,305$ and $243 \mathrm{~nm}$ with molar absorption coefficients 10,005, 5220 and 20,277, respectively. It was confirmed that the spectra are stable over time for at least a few days.

(b) Absorption Spectroscopy Studies in Water

The observed UV-Vis spectrum of 3-AF in water also has two distinct bands with maxima at $\lambda=352 \mathrm{~nm}$ and $\lambda=243 \mathrm{~nm}$. A comparison of this spectrum with the 3-AF spectrum in methanol confirms general similarities between these two spectra. A change in the position of the long-wave band with the maximum at $\lambda=352 \mathrm{~nm}$ can be observed, i.e., a hypsochromic shift of $12 \mathrm{~nm}$ (in methanol, 
the position was $\lambda=364 \mathrm{~nm}$ ). Moreover, ex tempore studies revealed that $3-\mathrm{AF}$ is poorly water soluble. It was estimated that at room temperature, solubility of $3-\mathrm{AF}$ is not higher than $8 \mu \mathrm{g} / \mathrm{mL}$. Thus, further fluorimetric studies were conducted in methanol, in which this compound dissolves relatively easily.

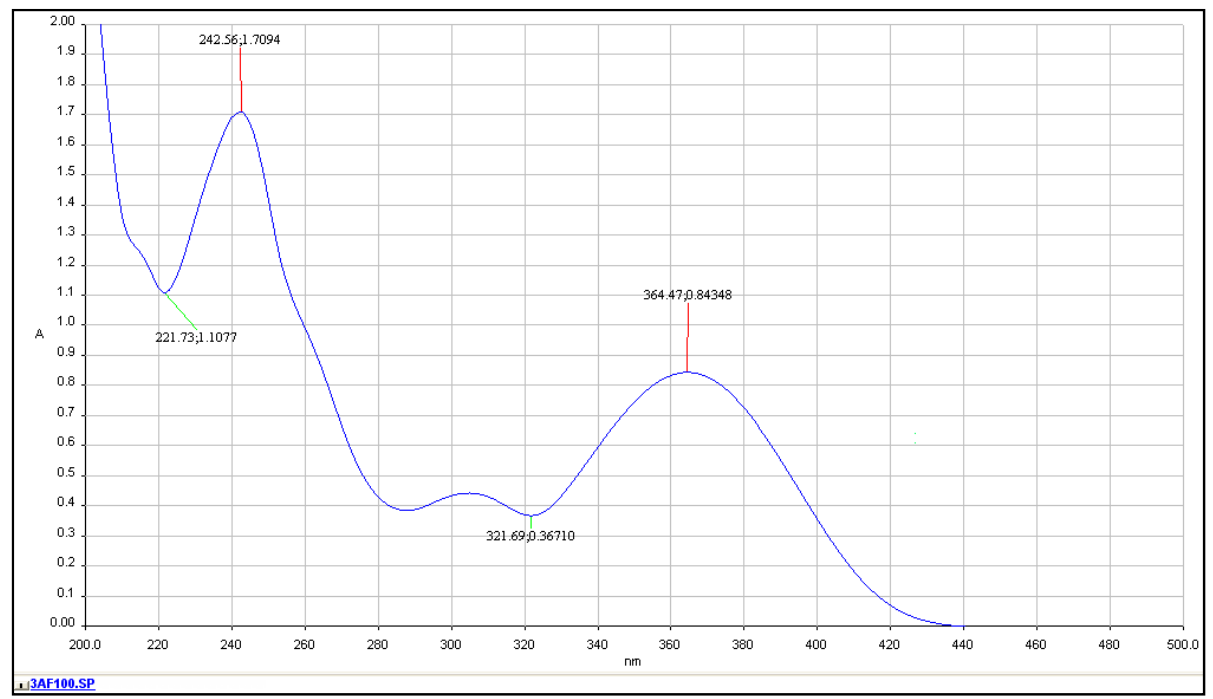

Figure 4. UV-Vis absorption spectrum of 3-aminoflavone in methanol at a concentration of $100 \mu \mathrm{g} / \mathrm{mL}$, in quartz cuvette with $\mathrm{l}=0.2 \mathrm{~cm}$, at temperature $\mathrm{t}=20^{\circ} \mathrm{C}$, with methanol as the reference.

\subsection{Three-Dimensional Fluorescence Spectra of 3-Aminoflavone in Methanol}

For the purpose of fluorimetric quantitative determination, it is necessary to calculate a pair of electromagnetic radiation wavelengths, for which fluorescence emission signal is maximal. The first is the wavelength of excitation fluorescence $\lambda_{\mathrm{ex}}$ and the other is the wavelength of emission fluorescence $\lambda_{\mathrm{em}}$. These values are read at the maximum of the strongest emission band, performed using the 3D technique. Figure 5 presents a 3D spectrum of 3-aminoflavone in methanol, with marked $\lambda_{\mathrm{ex}}$ and $\lambda_{\mathrm{em}}$ of the strongest emission band, measured with the use of Hitachi F4500 spectrofluorimeter. These wavelengths allowed for proper selection of filters for quantitative fluorescence measurements on a Jenway 6285 fluorimeter.

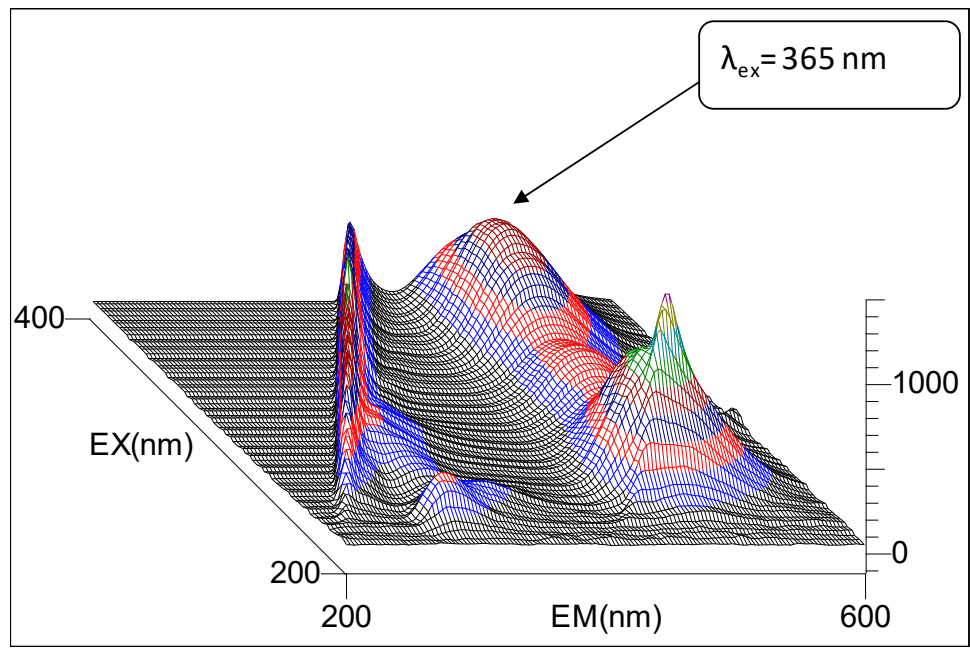

Figure 5. Three-dimensional spectrum of 3-aminoflavone in methanol. Intensity of fluorescence emission $\mathrm{I}_{\mathrm{f}}$ in RFU (relative fluorescence unit). Instrument parameters. Measurement type: 3D scan; data mode: Fluorescence; EX (Excitation) sampling interval: $3.0 \mathrm{~nm}$; EM (Emission) sampling interval: $3.0 \mathrm{~nm}$; scan speed: $1200 \mathrm{~nm} / \mathrm{min}$; EX slit: $5.0 \mathrm{~nm}$; EM slit: $5.0 \mathrm{~nm}$; PMT (Photomultiplier Tube) voltage: $700 \mathrm{~V}$; sensitivity: 1; threshold: 1.0 . 
It is easy to infer from the spectrum that the strongest fluorescence emission is observed for $\lambda_{\mathrm{ex}}=365 \mathrm{~nm}$ (excitation filter) and for $\lambda_{\mathrm{em}}=485 \mathrm{~nm}$ (analytical filter). These values are coordinates of the maximum of the strongest emission peak (Figure 5). The emission spectrum of 3-AF for the best excitation wavelength $\lambda_{\mathrm{ex}}=365 \mathrm{~nm}$ is presented in Figure 6.

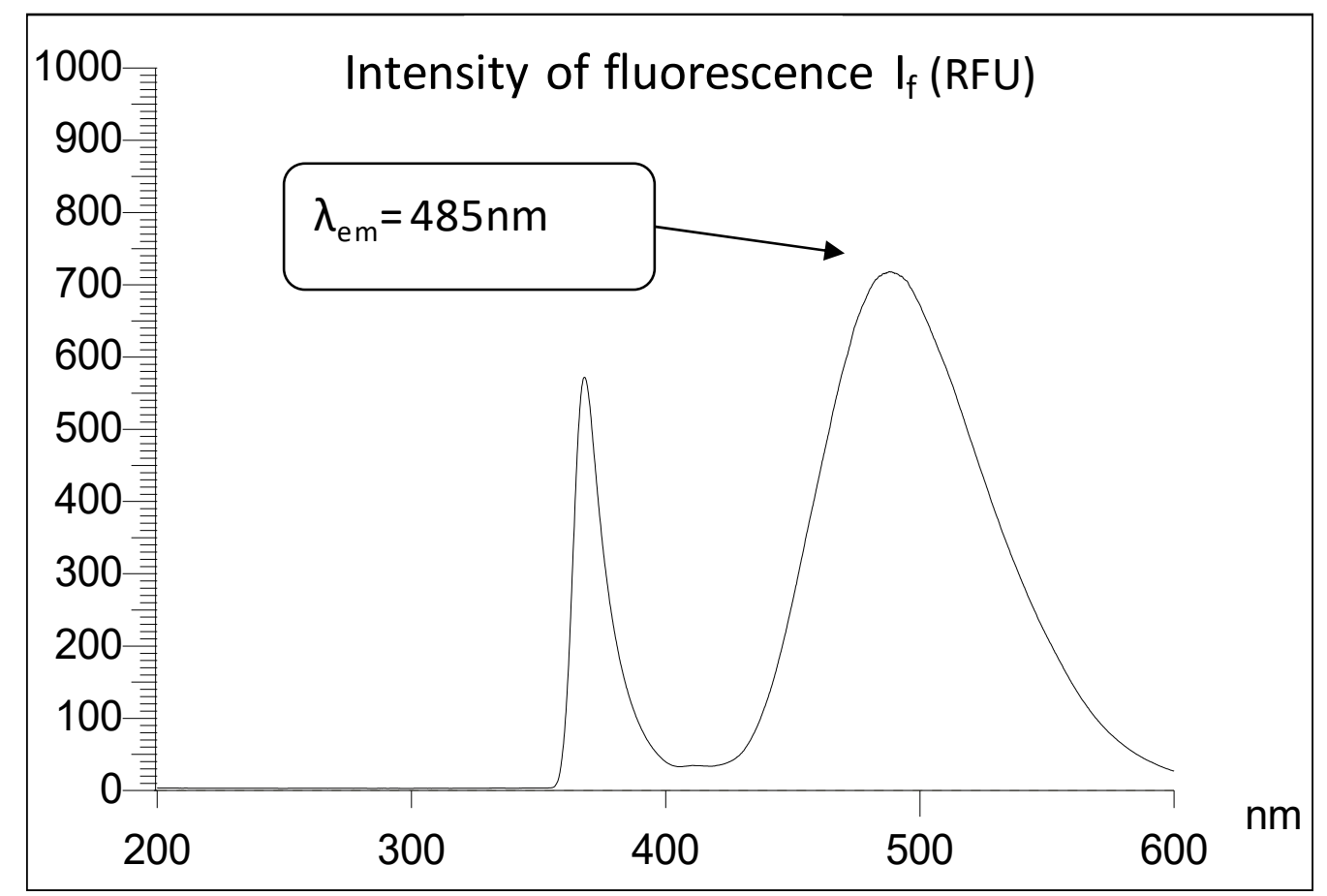

Figure 6. Emission spectrum of 3-aminoflavone in methanol at a concentration $\mathrm{c}=0.1 \mu \mathrm{g} / \mathrm{mL}$ in quartz cuvette with a thickness $1=1 \mathrm{~cm}$. Fluorescence excitation $\lambda_{\mathrm{ex}}=365 \mathrm{~nm}$; intensity of fluorescence emission $\mathrm{I}_{\mathrm{f}}$ is presented in RFU (relative fluorescence unit).

2.4. Determination of Limit of Detection (LOD) and Quantification (LOQ) of 3-Aminoflavone by the Fluorimetric Method

The limit of detection and the limit of quantification are basic parameters in the process of validation of analytical methods [19]. In order to determine LOD and LOQ, adopting linear dependence $y=(b x+a)$ (y and $x$ are dependent and independent variable, respectively), we should calculate direction coefficient $b$, absolute term $a$, errors of these coefficients $S_{b}, S_{a}$ and residual deviation $S_{y / x}$. These values are calculated according to the following formulas [19]:

$$
\begin{gathered}
b=\frac{n \sum x_{i} y_{i}-\sum x_{i} \sum y_{i}}{n \sum x_{i}^{2}-\left(\sum x_{i}\right)^{2}} a=\frac{1}{n}\left(\sum y_{i}-b \sum x_{i}\right) \\
S_{b}=\sqrt{\frac{n\left(\sum y_{i}^{2}-b \sum x_{i} y_{i}-a \sum y_{i}\right)}{(n-2)\left[n \sum x_{i}^{2}-\left(\sum x_{i}\right)^{2}\right]}} S_{a}=\sqrt{\frac{1}{n} S_{b}^{2} \sum x_{i}^{2}} \\
S_{y / x}=\sqrt{\frac{\sum\left(y_{i}-\hat{y}_{i}\right)^{2}}{(n-2)}} \text { where } \hat{y}_{i}=a \cdot x_{i}+b
\end{gathered}
$$

LOD can be calculated with two different methods, according to the formulas given below [20-22]:

$$
\begin{aligned}
& \text { a. method I: } \operatorname{LOD}=3.3 \cdot S_{a} / b \\
& \text { b. method II: } \operatorname{LOD}=3.3 \cdot S_{y / x} / b
\end{aligned}
$$


LOQ is a multiple of LOD, calculated according to the formula: LOQ $=3 \cdot \mathrm{LOD}$.

In order to determine LOD and LOQ with the application of the fluorimetric method, a Jenway 6285 fluorimeter was used, which was equipped with a set of light filters for the excitation and emission beam. Filters were selected for transmission corresponding to the wavelengths previously determined using the $3 \mathrm{D}$ spectrum. Thus, the excitation filter $\lambda_{\mathrm{ex}}$ was selected with transmission at a wavelength of $350 \mathrm{~nm}$, whereas the analytical filter $\lambda_{\mathrm{em}}=470 \mathrm{~nm}$.

In the preliminary experiment, the concentration range of 3-AF was determined, in which $\mathrm{I}_{\mathrm{f}}$ was a linear function of the concentration, by measuring emission spectra of a series of six solutions in methanol with a concentration ranging from $10 \mu \mathrm{g} / \mathrm{mL}$ to $60 \mu \mathrm{g} / \mathrm{mL}$, in steps of $10 \mu \mathrm{g} / \mathrm{mL}$-see Figure 7 .

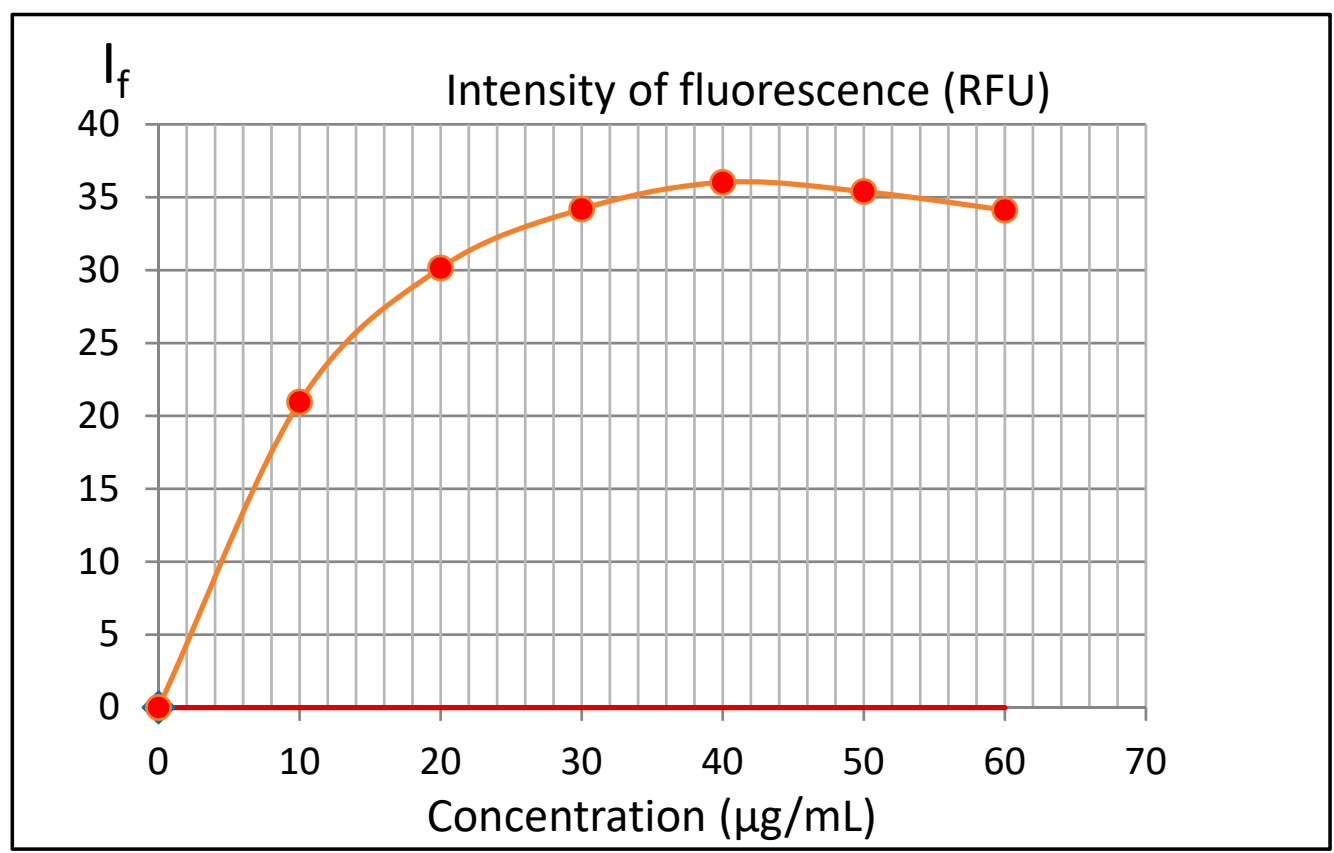

Figure 7. Intensity of fluorescence emission $\mathrm{I}_{\mathrm{f}}$ as a function of 3-aminoflavone concentration in methanol. The fluorescence was measured in cuvette with a path length $1 \mathrm{of} 1 \mathrm{~cm}$. For excitation and emission, filters with wavelengths of $350 \mathrm{~nm}$ and $470 \mathrm{~nm}$ were used, respectively.

The above plot clearly shows the effect of concentration quenching. For concentrations above $10 \mu \mathrm{g} / \mathrm{mL}$, the $\mathrm{I}_{\mathrm{f}}$ value is no longer linear and for concentrations above $40 \mu \mathrm{g} / \mathrm{mL}$, due to further concentration quenching, fluorescence emission $\mathrm{I}_{\mathrm{f}}$ even decreases.

In order to determine the LOD and LOQ values, a series of ten solutions of 3-AF in methanol was analyzed, ranging from $1 \mu \mathrm{g} / \mathrm{mL}$ to $10 \mu \mathrm{g} / \mathrm{mL}$, in steps of $1 \mu \mathrm{g} / \mathrm{mL}$. Figure 8 presents fluorescence intensity $\mathrm{I}_{\mathrm{f}}$ measurements as the function of 3-AF concentration.

In the presented study, linear regression was used (EXCEL 2010, REGLINP function). In order to determine LOD and LOQ, direction coefficient $b$, absolute term $a$, corresponding error $S_{a}$ and the coefficient of determination $\mathrm{R}^{2}$ were calculated. For the purpose of the alternative method of determining LOD and LOQ, $S_{y / x}$ was also calculated. The calculated coefficients $b$ and a and corresponding errors $S_{a}$ and $S_{y / x}$ are the following:

$$
\mathrm{b}=1.9129 \pm 0.06258 ; \mathrm{a}=1.2783 \pm 0.3702 ; \mathrm{S}_{\mathrm{a}}=0.3702 ; \mathrm{S}_{\mathrm{y} / \mathrm{x}}=0.6563
$$

The value of the calculated coefficient of determination $\mathrm{R}^{2}=0.9905$ means that the adopted linear model is well adjusted to experimental results. Considering the above results, one can determine LOD and LOQ values with two methods. 


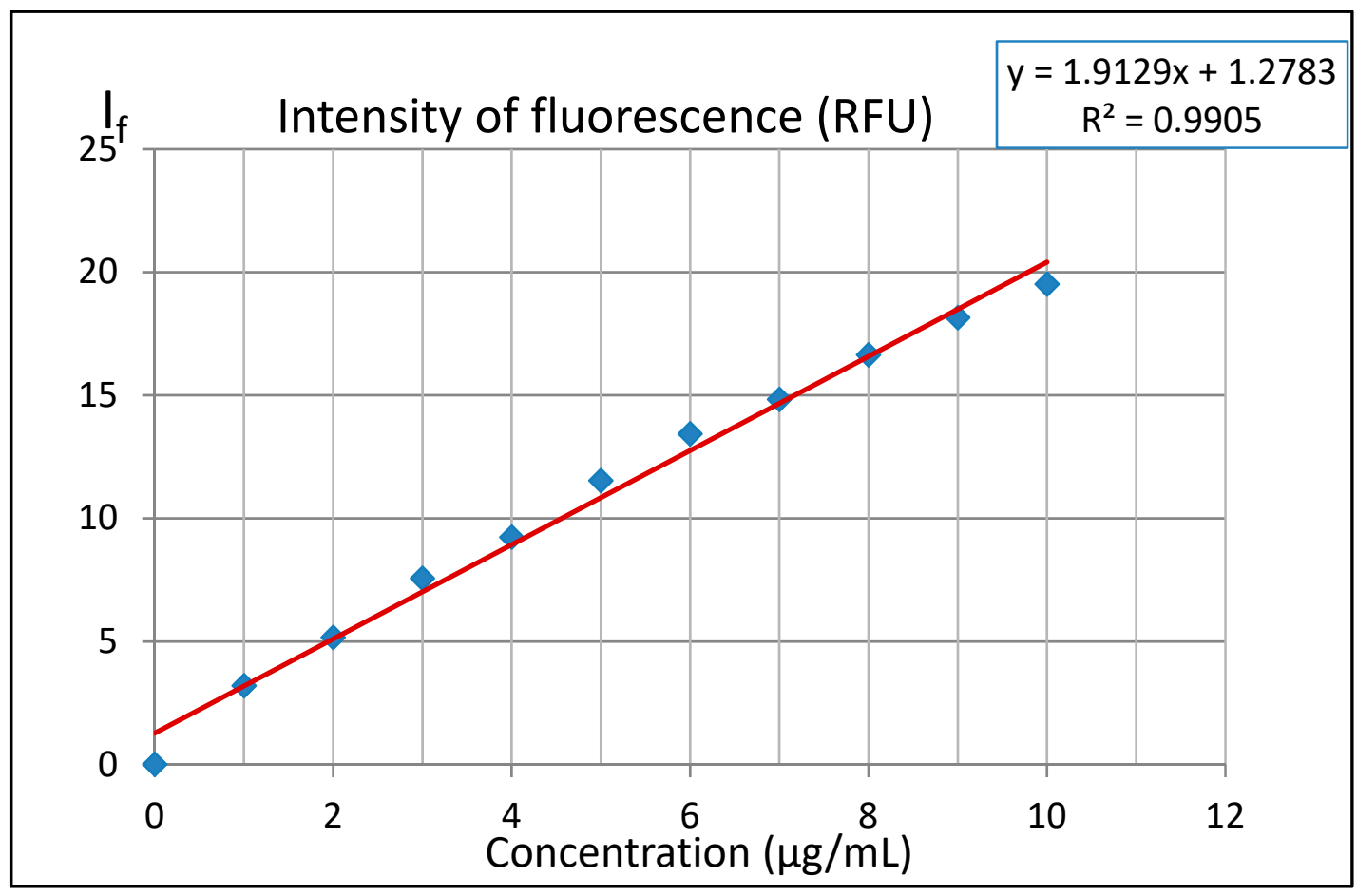

Figure 8. Fluorescence emission intensity dependence as a function of 3-aminoflavone concentration in methanol fitted with a linear function. The cuvette thickness 1 was $1 \mathrm{~cm}$. For excitation and emission, filters with wavelengths of $350 \mathrm{~nm}$ and $470 \mathrm{~nm}$ were used, respectively.

Method I with the use of $S_{a}$ : For $b=1.9129$ and $S_{a}=0.3702$ allows to obtain:

$$
\mathrm{LOD}=3.3 \cdot \mathrm{S}_{\mathrm{a}} / \mathrm{b} \approx 0.64 \mu \mathrm{g} / \mathrm{mL} ; \mathrm{LOQ}=3 \cdot \mathrm{LOD} \approx 1.92 \mu \mathrm{g} / \mathrm{mL}
$$

Method II with the use of $S_{y / x}:$ For $b=1.9129$ and $S_{y / x}=0.6563$ allows to obtain:

$$
\mathrm{LOD}=3.3 \cdot \mathrm{S}_{\mathrm{y} / \mathrm{x}} / \mathrm{b} \approx 1.13 \mu \mathrm{g} / \mathrm{mL} ; \mathrm{LOQ}=3 \cdot \mathrm{LOD} \approx 3.40 \mu \mathrm{g} / \mathrm{mL}
$$

2.5. Determination of Limit of Detection (LOD) and Limit of Quantification (LOQ) of 3-Aminoflavone with UV-Vis Spectroscopy

In order to determine LOD and LOQ of the 3-AF compound with the UV-Vis spectroscopic method, a series of solutions of 3-AF in methanol, with concentrations ranging from 10 to $100 \mu \mathrm{g} / \mathrm{mL}$, in steps every $10 \mu \mathrm{g} / \mathrm{mL}$ was prepared. The concentrations were selected in such a way that they allowed to determine the absorbance values to remain within the recommended range of $0.5-2$ absorbance units A. Calculations were made for the strongest band, with a maximum at $\lambda=364 \mathrm{~nm}$. Figure 9 shows the dependence of absorbance $\mathrm{A}(\lambda=364 \mathrm{~nm})$ as a function of 3-AF concentration.

Similar to the previous procedure, direction coefficient $b$, absolute term a and corresponding errors $S_{a}$ and $S_{y / x}$ were calculated using REGLINP function in the EXCEL spreadsheet. The following values were obtained:

$$
\mathrm{b}=0.00801 \pm 0.00005 ; \mathrm{a}=0.01253 \pm 0.00300 ; \mathrm{S}_{\mathrm{a}}=0.00300 ; \mathrm{S}_{\mathrm{y} / \mathrm{x}}=0.00533
$$

The calculated coefficient of determination $R^{2}=0.9996$ means that the adopted model is well adjusted to experimental results. Considering the above results, as in the fluorimetric calculations, LOD and LOQ values were obtained with two methods. 


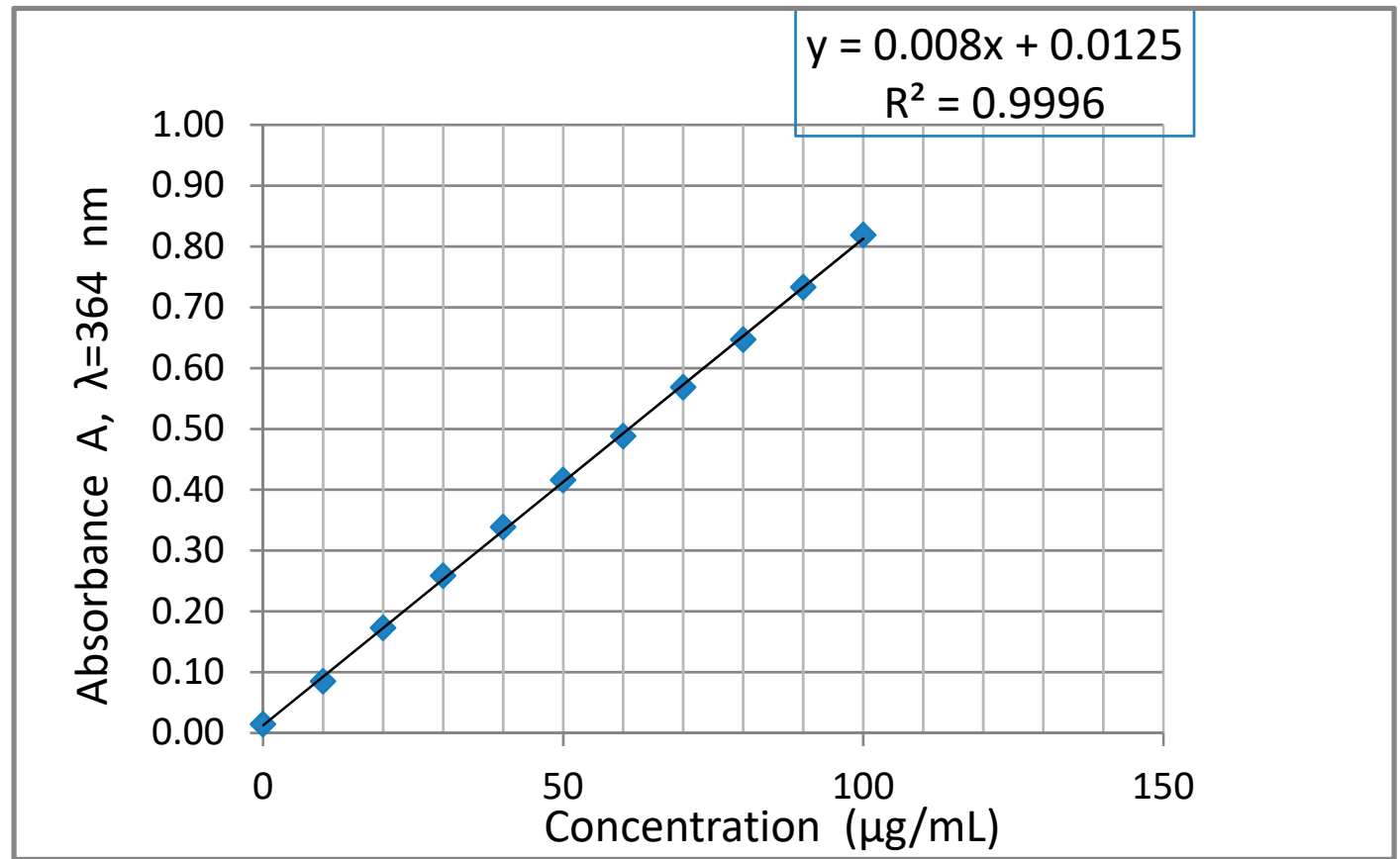

Figure 9. Dependence of absorbance A at $\lambda=364 \mathrm{~nm}$ as the function of 3-aminoflavone concentration in methanol. The quartz cuvette thickness 1 was $0.2 \mathrm{~cm}$.

Method I with the use of $S_{a}$ : For $b=0.00801$ and $S_{a}=0.00300$ allows to obtain:

$$
\mathrm{LOD}=3.3 \cdot \mathrm{S}_{\mathrm{a}} / \mathrm{b} \approx 1.24 \mu \mathrm{g} / \mathrm{mL}, \mathrm{LOQ}=3 \cdot \mathrm{LOD} \approx 3.71 \mu \mathrm{g} / \mathrm{mL}
$$

Method II with the use of $\mathrm{S}_{\mathrm{y} / \mathrm{x}}$ : For $\mathrm{b}=0.00801$ and $\mathrm{S}_{\mathrm{y} / \mathrm{x}}=0.00533$ allows to obtain:

$$
\mathrm{LOD}=3.3 \cdot \mathrm{S}_{\mathrm{y} / \mathrm{x}} / \mathrm{b} \approx 2.20 \mu \mathrm{g} / \mathrm{mL} ; \mathrm{LOQ}=3 \cdot \mathrm{LOD}=3 \cdot 2.20 \mu \mathrm{g} / \mathrm{mL}=6.60 \mu \mathrm{g} / \mathrm{mL}
$$

\subsection{Studies on the Influence of $p H$ on Fluorescence of 3-Aminoflavone Solutions}

In order to evaluate the effect of $\mathrm{pH}$ on fluorescence of 3-AF, a solution of 3-AF in $5 \mathrm{~mL}$ of methanol at a concentration of $10 \mu \mathrm{g} / \mathrm{mL}$ and a water solution of $\mathrm{HCl}$ at a concentration $0.2 \mathrm{~mol} / \mathrm{L}$ were prepared. After dilution, the $\mathrm{HCl}$ concentration decreased twofold, to the value of $0.1 \mathrm{~mol} / \mathrm{L}$, which results in $\mathrm{pH} \approx 1$ and $3-\mathrm{AF}$ concentration of $5 \mu \mathrm{g} / \mathrm{mL}$. For this solution, the 3D fluorescence spectrum was determined as well as optimal values for excitation, i.e., $\lambda_{\mathrm{ex}}=356 \mathrm{~nm}$ and emission $\lambda_{\mathrm{em}}=488 \mathrm{~nm}$ were calculated. These values are similar to those obtained for methanol solution, i.e., 365 and $485 \mathrm{~nm}$, respectively.

Thus, to evaluate the effect of $\mathrm{pH}$ on fluorescence of 3-AF, a series of solution spectra of 3-AF in $5 \mathrm{~mL}$ of methanol at a concentration of $10 \mu \mathrm{g} / \mathrm{mL}$ and $5 \mathrm{~mL}$ of $\mathrm{HCl}$ with concentrations of $0.2,0.02$, $0.002,0.0002$ and $0.00002 \mathrm{~mol} / \mathrm{L}$ were measured. After dilution, $\mathrm{pH}$ values of these solutions were around 1, 2, 3, 4 and 5, respectively. Figure 10 presents the relationship between fluorescence intensity $\mathrm{I}_{\mathrm{f}}$ and $\mathrm{pH}$.

The plot shows that an increase in the acidity of a solution is accompanied by a rapid decrease in 3-AF fluorescence. For $\mathrm{pH}=1$ it is about 8 times weaker than for $\mathrm{pH}=5$. Similar experiments were conducted for solutions in which hydrochloric acid was replaced by sulfuric acid. Moreover, here a strong decrease in 3-AF fluorescence was observed. Thus, it can be concluded that fluorescence quenching is caused not by a chloride anion, although the influence of some anions, particularly halide anions, is known, but hydronium ions $\mathrm{H}_{3} \mathrm{O}^{+}$. In order to analyze this phenomenon, $\mathrm{UV}-\mathrm{Vis}$ spectra of 3-aminoflavone in these solutions were measured- see Figure 11. 


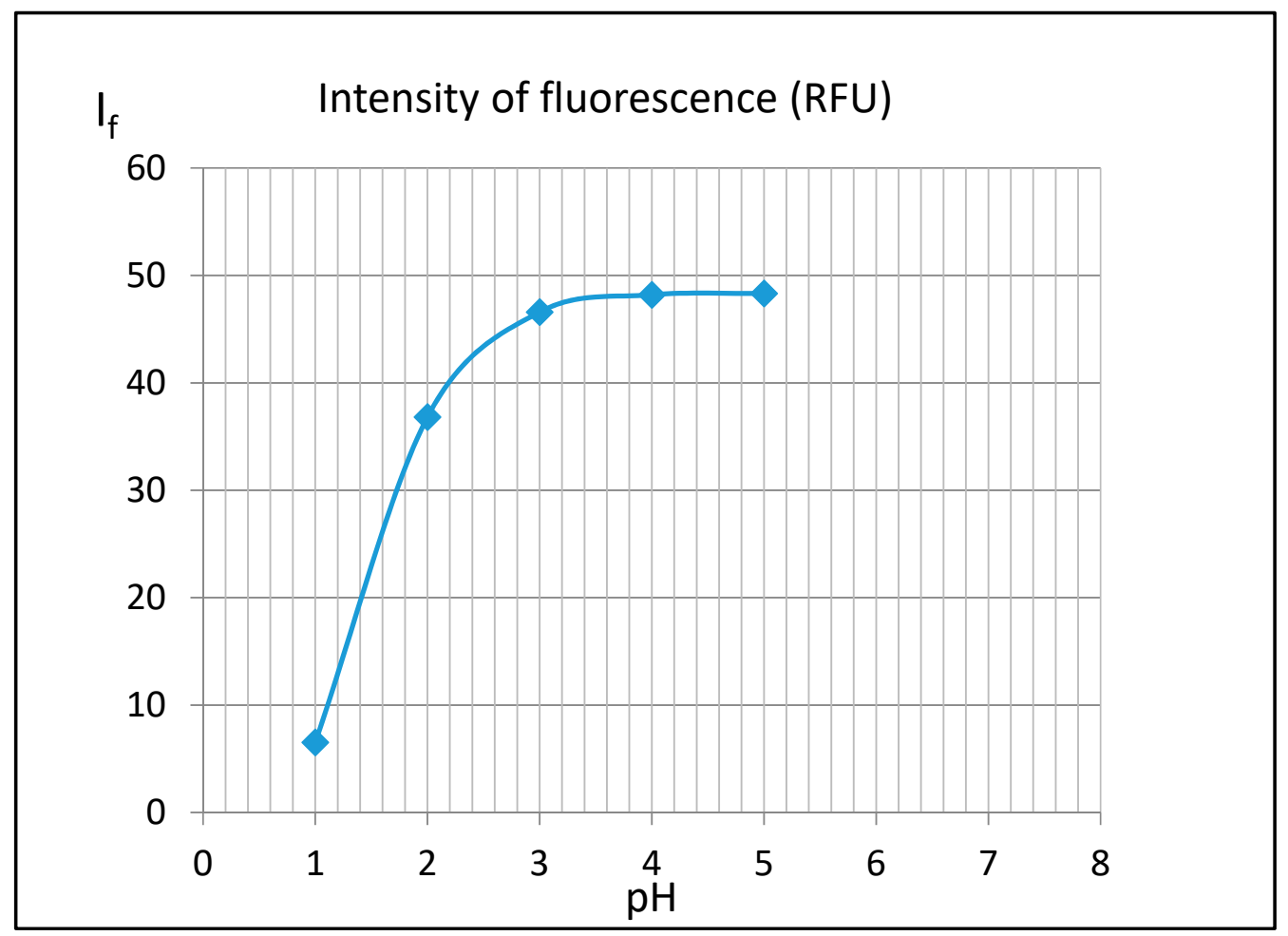

Figure 10. Relationship between fluorescence intensity $\mathrm{I}_{\mathrm{f}}$ of 3-aminoflavone and $\mathrm{pH}$. For excitation and emission, filters with wavelengths of $350 \mathrm{~nm}$ and $470 \mathrm{~nm}$ were used, respectively.

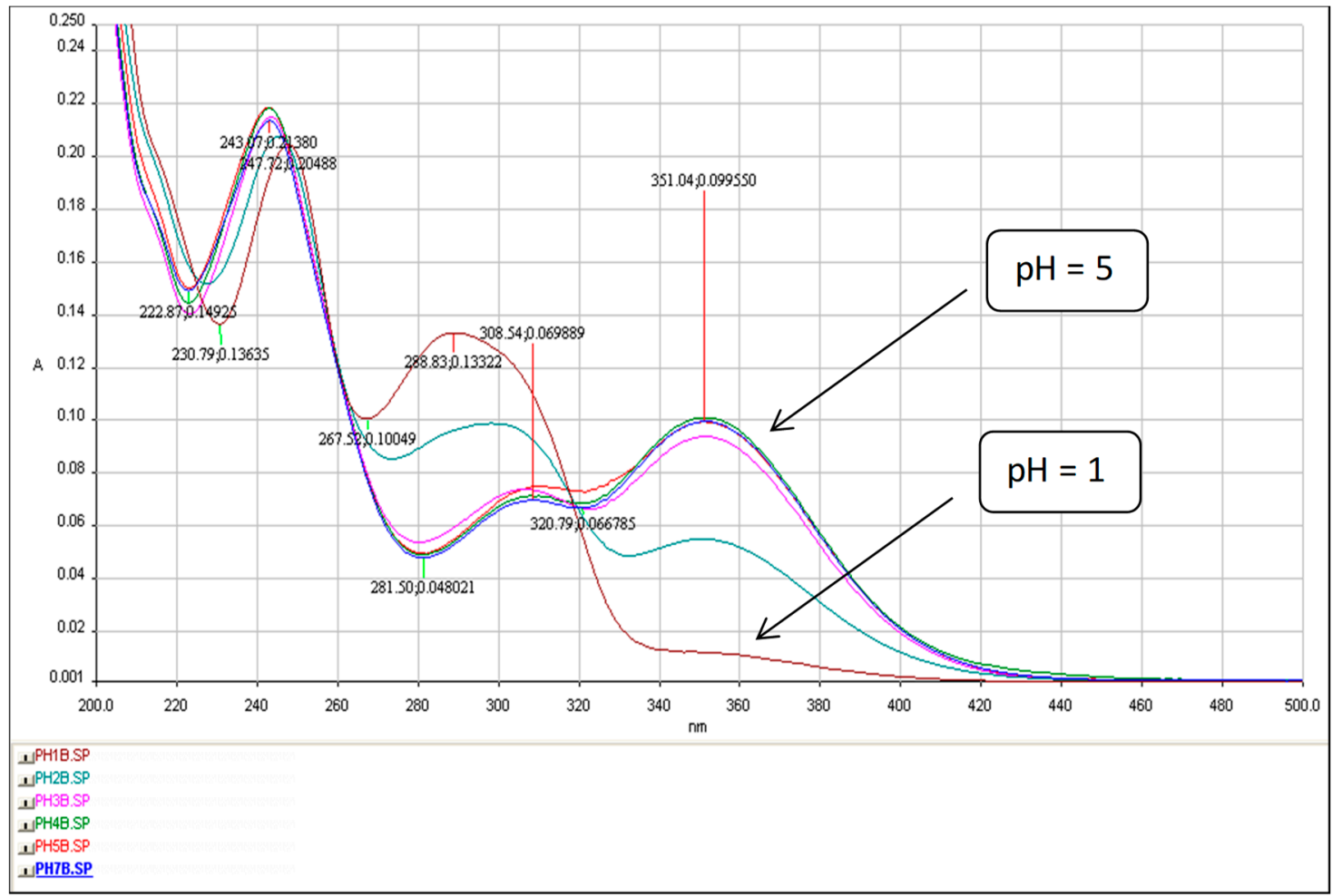

Figure 11. UV-Vis spectra of 3-aminoflavone $(\mathrm{c}=5 \mu \mathrm{g} / \mathrm{mL})$ in $\mathrm{HCl}$ solutions at $\mathrm{pH}=1,2,3,4,5$. $1=1 \mathrm{~cm}$.

The plot clearly shows isosbestic points at $\lambda \approx 245,260$ and $320 \mathrm{~nm}$. It confirms the presence of acid-base balance (mixture of neutral and protonated forms of 3-AF). Based on this plot, it can be 
concluded that, for the band with a maximum at $\lambda \approx 350 \mathrm{~nm}$, an increase in acidity (decreasing $\mathrm{pH}$ ) is associated with a strong decrease in the absorbance value A. A strong decrease in fluorescence can be explained by the accompanied increase in the acidity of the solutions. The protonated form of 3-AF practically has no absorption band at $\lambda \approx 350 \mathrm{~nm}$, which is used for fluorescence excitation of the 3-AF molecule.

\subsection{Influence of Halide Anions on Fluorescence of 3-Aminoflavone}

It is generally known that the environment can considerably affect emission spectra of a studied solution considering the position of emission bands and intensities. This influence is particularly strong for solutions containing halide anions. For example, chloride ions are a commonly known quenching agent for quinine [23].

In this study, an attempt to evaluate an influence of the concentration of these anions on the intensity of 3-AF fluorescence was also made. Mixtures of 3-AF solution in methanol with the corresponding halide anion solutions were prepared. A solution of 3-AF in methanol at a concentration of $10 \mu \mathrm{g} / \mathrm{mL}$ was used as a working solution. Next, to $5 \mathrm{~mL}$ of this solution a proper amount of aqueous solution of the particular anion was added. The mixture was filled with water to obtain $10 \mathrm{~mL}$ of a halide solution. For example, to prepare the solution with a chloride concentration of $0.1 \mathrm{~mol} / \mathrm{L}$, $1 \mathrm{~mL}$ of chloride solution with a concentration of $1 \mathrm{~mol} / \mathrm{L}, 5 \mathrm{~mL}$ of 3 -AF solution and $4 \mathrm{~mL}$ of distilled water were mixed to obtain the final $10 \mathrm{~mL}$ solution. The concentration of 3-AF in all experiments was always $5 \mu \mathrm{g} / \mathrm{mL}$, i.e., a double dilution of the 3-AF solution. Results of halide concentration on fluorescence of 3-AF are presented in Figure 12.

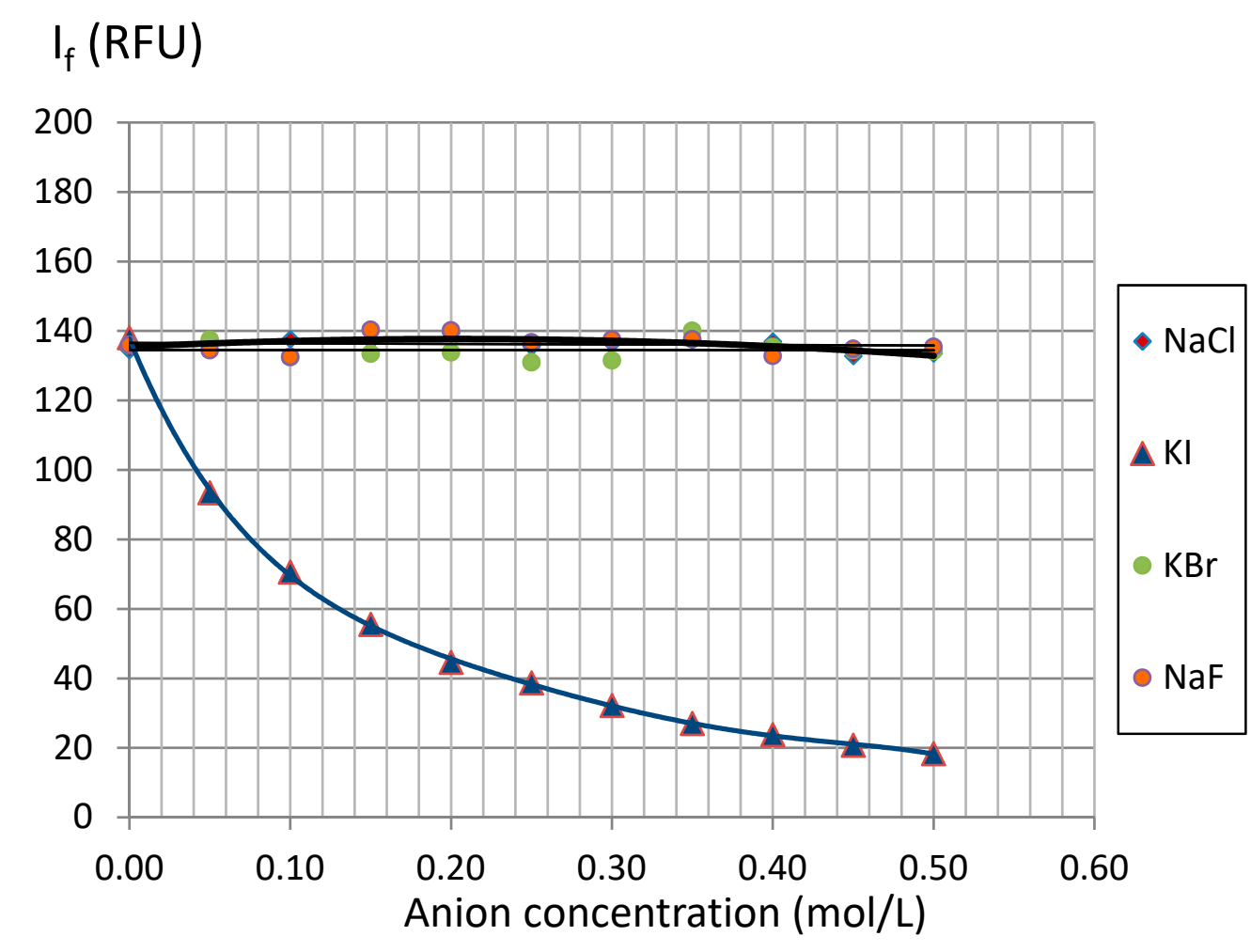

Figure 12. The relationship between fluorescence intensity $\mathrm{I}_{\mathrm{f}}$ of 3-aminoflavone and the concentration of chloride, bromide, iodide and fluoride ions. The concentration of 3-aminoflavone was $5 \mu \mathrm{g} / \mathrm{mL}$ in cuvette with a path length of $1 \mathrm{~cm}$. For excitation and emission, filters with wavelengths of $350 \mathrm{~nm}$ and $470 \mathrm{~nm}$ were used, respectively. 
It can be observed that the presence of anions such as chloride, bromide and fluoride does not affect the fluorescence of 3-AF. However, strong fluorescence quenching by iodide ions was noted. In solution with iodide anions and concentration $\mathrm{c}=0.5 \mathrm{~mol} / \mathrm{L}$, fluorescence intensity decreases from $138 \mathrm{RFU}$ to $18 \mathrm{RFU}$, and this decay is almost eightfold. The mechanism of fluorescence quenching by iodide ions has been described by J. Najbar and M. Mac [24]. According to these authors, the phenomena are associated with the so-called external heavy-atom effect and with transferring the electron from the anion to the excited compound molecule. However, we would like to pay attention to another possible reason for the 3-AF quenching phenomenon. The $1 \mathrm{~mol} / \mathrm{L} \mathrm{KI}$ solution prepared for testing tends to change after a few hours from preparation to a slight yellow colour (oxidation of iodides to free iodine). The UV-Vis spectrum made for this solution has a wide absorption band with a maximum at $\lambda \approx 352 \mathrm{~nm}$. This is nearly the wavelength of the radiation used to excite $3-\mathrm{AF}(\lambda=350 \mathrm{~nm})$ and very close to the location of the maximum of the long-term absorption band 3-AF $(\lambda=364 \mathrm{~nm})$. It should be noted that the concentration of the KI solution $(1 \mathrm{~mol} / \mathrm{L})$ is greater by several orders of magnitude than that of the examined compound $-5 \mu \mathrm{g} / \mathrm{mL}\left(2.11 \cdot 10^{-5} \mathrm{~mol} / \mathrm{L}\right)$. The trace amounts of free iodine in the examined solution are therefore a "competitive" source of absorption of the radiation needed to excite the molecule of 3-AF and may be responsible for the fluorescence quenching.

Quantitative determinations of 3-aminoflavone cannot be performed in an aqueous environment because the compound is poorly soluble in water. Hence, in experiments we used methyl alcohol, in which this solubility is sufficient. The fluorimetric method cannot be applied for quantitative determinations if 3-AF concentration exceeds $40 \mu \mathrm{g} / \mathrm{mL}$. At higher concentrations, the fluorescence intensity $\mathrm{I}_{\mathrm{f}}$ decreases with increasing $3-\mathrm{AF}$ concentration. We stated that the linear range of fluorescence intensity $I_{\mathrm{f}}$ vs concentration of 3-AF is limited to concentrations up to $10 \mu \mathrm{g} / \mathrm{mL}$. The LOD calculated for this range was $0.64 \mu \mathrm{g} / \mathrm{mL}$ (the method with the use of $S_{a}$ ) or $1.92 \mu \mathrm{g} / \mathrm{mL}$ (the method with the use of $\mathrm{S}_{\mathrm{y} / \mathrm{x}}$ ). The LOQ values were 1.13 and $3.40 \mu \mathrm{g} / \mathrm{mL}$, respectively.

With regard to spectrophotometric measurements, the range of linear dependence of absorbance A on the concentration of 3-AF is much higher and reaches at least $100 \mu \mathrm{g} / \mathrm{mL}$. Calculated LOD values were $1.24 \mu \mathrm{g} / \mathrm{mL}$ (the method with the use of $S_{a}$ ) and $3.71 \mu \mathrm{g} / \mathrm{mL}$ (the method with the use of $S_{y / x}$ ), respectively. The LOQ values are 2.20 and $6.59 \mu \mathrm{g} / \mathrm{mL}$, respectively. It can be seen that these values are much higher ("worse") than those obtained with the application of the fluorimetric method.

The relationship between $\mathrm{pH}$ and 3-AF fluorescence was also analyzed. It is associated with protonation of 3-AF molecules, which manifests itself in clearly visible isosbestic points at $\lambda \approx 245$, 260 and $320 \mathrm{~nm}$. Changes in absorption UV-Vis spectra, related to different $\mathrm{pH}$ values, confirm this phenomenon.

The effect of halide anions on luminescence quenching of 3-AF was analyzed. No significant effect of chloride, bromide or fluoride ions on fluorescence emission was observed. However, a strong fluorescence quenching by iodide ions was noted.

\section{Materials and Methods}

\subsection{Materials}

The 3-aminoflavone compound (IUPAC name: 3-amino-2-phenylchromen-4-one, $\mathrm{C}_{15} \mathrm{H}_{11} \mathrm{NO}_{2}$, molar mass: $237.258 \mathrm{~g} / \mathrm{mol}$; PubChem CID: 248316), referred to as 3-AF, is a flavonoid compound whose structural formula is presented in Figure 1.

The 3-aminoflavone compound was synthesized and purified in our laboratory, and was used as a ligand in many metal complexes. Macroscopically, 3-aminoflavone is yellow and crystalline solid. The crystals are needle shaped, and their melting point ranges between 140 and $142{ }^{\circ} \mathrm{C}$. It is significantly soluble in most organic solvents, but poorly soluble in water. The photophysical and electron properties of 3-AF have been recently reported [25]. The authors described results of theoretical as well as experimental studies. The theoretical calculations were made using the TD DFT model (time-dependent density functional theory). This low-cost calculation method, due to an effective 
electron correlation, allowed to obtain a reliable description of ground and excited states of the molecule, the transition energies, electron densities and HOMO (highest occupied molecular orbital)/LUMO (lowest unoccupied molecular orbital) energy levels. In this study, an influence of the polarity of solvents on the absorption and emission spectra of 3-AF was also established. The solvent effect is less significant for absorption spectra and more pronounced for fluorescence spectra. For example, the maximum absorption of 3-AF in hexane is observed at the wavelength $\lambda_{\max }=359 \mathrm{~nm}$, while in the case of the aqueous solution, it is at $\lambda_{\max }=353 \mathrm{~nm}$. For fluorescence spectra the maximum emission of 3-AF in hexane is $\lambda_{\mathrm{em}}=425 \mathrm{~nm}$ and for the aqueous solution it is $\lambda_{\mathrm{em}}=490 \mathrm{~nm}$.

It this work, we present the results of 3-AF fluorescence emission in methanol as a function of $\mathrm{pH}$ and halogen ion concentration as well as the method for the quantitative determination of 3-AF concentration.

\subsection{Methods}

The data of single crystal X-ray diffraction were collected on a Bruker AXS Smart Apex II CCD diffractometer (Karlsruhe, Germany) with Incoatec I $\mu \mathrm{S} C \mathrm{Cu}-\mathrm{K} \alpha(\lambda=1.54178 \AA)$ as a source of radiation. The structure was solved by the direct method and subsequent Fourier syntheses and refined by full-matrix least squares on F2 using the SHELXS-2012 and SHELXL-2012 programs [26]. The scattering factors were those given in the SHELXL program (Goettingen, Germany). All non-hydrogen atoms were refined anisotropically. Hydrogen atoms were generated geometrically and refined as riding atoms with isotropic displacement factors equivalent to 1.2 times those of the atom to which they were attached, except for the two in the amine group, which were allowed to refine freely. Graphics were produced with XShell14 and CCDC Mercury (Cambridge, UK) [27,28].

Crystal data for 1o (3-AF polymorph): $\mathrm{C}_{15} \mathrm{H}_{11} \mathrm{NO}_{2}, \mathrm{M}=237.25$, orthorhombic, a $=4.1492(4)$, $\mathrm{b}=12.9988(12), \mathrm{c}=21.256(2) \AA, \mathrm{V}=1146.46(19) \AA^{3}, \mathrm{~T}=296(5) \mathrm{K}$, space group $\mathrm{P} 22_{1} 2_{1} 2_{1}$ (no. 19), $\mathrm{Z}=4$, 12,758 reflections were measured, 2123 were unique $\left(R_{\text {int }}=0.0431\right)$ and 2049 were greater than $2 \sigma\left(\mathrm{F}^{2}\right)$. The final anisotropic full-matrix least-squares refinement on $\mathrm{F}^{2}$ with 172 variables converged at $R_{1}=0.0353$ for the observed data and $w \mathrm{R}_{2}=0.1019$ for all data. The CCDC deposition number was 1037205 .

Fluorescence spectra were measured with the use a Jenway 6285 fluorimeter (spectral range from 190 to 850 nm, Gransmore Green Felsted Dunmow, UK) and Hitachi F4500 spectrofluorimeter (Tokio, Japan), which allows to record complex fluorescence spectra in the 2D and 3D techniques. UV-Vis spectra were registered on a UV-VIS Lambda 25 spectrophotometer (PerkinElmer, Waltham, Massachusetts, USA) in the range from 200 to $800 \mathrm{~nm}$. UV-Vis absorption, as well as fluorescence spectra in the 3D technique, were measured in quartz cuvettes in the full transmission spectral range, $\lambda>200 \mathrm{~nm}$. For quantitative fluorescence measurements, special plastic cuvettes with transmission $\lambda>300 \mathrm{~nm}$ were used.

\section{Conclusions}

In conclusion we elaborated a convenient method for quantitative determination of 3-aminoflavone (3-AF). We demonstrated that absorption and emission spectroscopy can be applied for determination of 3-AF. This is important in view of the ability of 3-AF to form coordination compounds with $\mathrm{p}-$, $\mathrm{d}$ and f-electron metal ions, which makes it an interesting component for analytical chemistry. Recently, we reported on the biological activity of the platinum(II) chloride complex of 3-AF as a potential anticancer drug. Our study on 3-aminoflavone could be a basis for further investigation of 3-AF as a powerful tool in a fluorimetric detection of metal complexes or new chemotherapeutics.

Author Contributions: Conceptualization, W.P. and J.O.; methodology, W.P. and J.W.; validation, W.P. and J.W.; formal analysis, W.P.; data curation W.P. and J.W.; writing-original draft preparation, W.P., M.F. and J.W.; writing-review and editing, J.O., W.P., M.F. and W.M.W.; supervision, A.K. and E.B.

Funding: This work was supported partly by Medical University of Lodz grants statute no.503/3-016-02/503-01, 503/3-045-01/503-31-001-17 and 503/3-016-03/503-31-001-18. 
Acknowledgments: The authors thank Adam Darago (Department of Toxicology, Medical University, Łódź) and Karolina Brzezińska for his helpful assistance with fluorescent measurements.

Conflicts of Interest: The authors declare no conflict of interest.

\section{References}

1. Havsteen, B. Flavonoids, a class of natural products of high pharmacological potency. Biochem. Pharmacol. 1983, 32, 1141-1148. [CrossRef]

2. Nijveldt, P.; Nood, E.; Hoorn, D.E.C.; Boelens, P.G.; Norren, K.; Leeven, P.A.M. Flavonoids: A review of probable mechanisms of action and potential applications. Am. J. Clin. Nutr. 2001, 74, 418-425. [CrossRef] [PubMed]

3. Kośmider, B.; Osiecka, E. Flavonoid compounds: A review of anticancer properties and interactions with cis-diamminedichloroplatinum(II). Drug Dev. Res. 2004, 63, 200-211. [CrossRef]

4. Paszkiewicz, M.; Budzyńska, A.; Różalska, B.; Sadowska, B. Immunomodulacyjna ola polifenoli roślinnych. Postępy Hig. Med. Dośw. 2012, 66, 637-646. [CrossRef]

5. Nowak, A.; Zielonka, J.; Turek, M.; Klimowicz, A. Wpływ przeciwutleniaczy zawartych w owocach na proces fotostarzenia się skóry. Postępy Fitoterapii 2014, 2, 94-99.

6. Kasprzak, M.M.; Erxleben, A.; Ochocki, J. Properties and applications of flavonoid metal complexes. R. Soc. Chem. Adv. 2015, 5, 45853-45877. [CrossRef]

7. Fabijańska, M.; Studzian, K.; Szmigiero, L.; Rybarczyk-Pirek, A.J.; Pfitzner, A.; Cebula-Obrzut, B.; Smolewski, P.; Zyner, E.; Ochocki, J. Trans-Platinum(II) complex of 3-aminoflavone-synthesis, X-ray crystal structure and biological activities in vitro. Dalton Trans. 2015, 44, 938-947. [CrossRef] [PubMed]

8. Wong, E.; Giandomenico, C.M. Current status of platinum-based antitumor. Drugs Chem. Rev. 1999, 99, 2451-2466. [CrossRef] [PubMed]

9. Galański, M.; Keppler, B.K. Searching for the Magic Bullet: Anticancer Platinum Drugs Which Can Be Accumulated or Activated in the Tumor Tissue. Med. Chem. 2007, 7, 55-73. [CrossRef]

10. Kalinowska-Lis, U.; Ochocki, J.; Matławska-Wasowska, K. Trans geometry in Platinum antitumor complexes. Coord. Chem. Rev. 2008, 252, 1328-1345. [CrossRef]

11. Kośmider, B.; Osiecka, R.; Zyner, E.; Ochocki, J. Comparison between the genotoxicity of cis-Pt(ll) complex of 3-aminoflavone and cis-DDP in lymphocytes evaluated by the comet assay. Chem. Toxicol. 2005, 28, 231-244. [CrossRef] [PubMed]

12. Dauzonne, D.; Folléas, B.; Martinez, L.; Chabot, G.G. Synthesis and in vitro Cytotoxicity of a Series of 3-Aminoflavones. Euro. J. Med. Chem. 1997, 32, 71-82. [CrossRef]

13. Żurowska, B.; Erxleben, A.; Glinka, Ł.; Łeczycka, M.; Zyner, E.; Ochocki, J. Synthesis, spectroscopy and magnetism of novel metal complexes of 3-aminoflavone (3-af). X-ray crystal structure of 3-af and [Cu (3-af) 2 $\left(\mathrm{NO}_{3}\right)_{2}$ ]. Inorg. Chim. Acta 2009, 362, 739-744. [CrossRef]

14. Ochocki, J.; Kasprzak, M.; Chęcińska, L.; Erxleben, A.; Zyner, E.; Szmigiero, L.; Garza-Ortiz, A.; Reedijk, J. Synthesis, single-crystal and solution structure analysis and in vitro cytotoxic activity of two novel complexes of ruthenium(II) with in situ formed flavanone-based ligands. Dalton Tran. 2010, 39, 9711-9718. [CrossRef] [PubMed]

15. Pyrzynska, K.; Pękal, A. Flavonoids as Analytical Reagents. Crit. Rev. Anal. Chem. 2011, 41, $335-345$. [CrossRef]

16. Malesev, D.; Kunti, V. Investigation of metal-flavonoid chelates and the determination of flavonoids via metal-flavonoid complexing reactions. J. Serb. Chem. Soc. 2007, 72, 921-939. [CrossRef]

17. Stone, M.; Rhia, L.; Butler, M.S.; Phetsang, W.; Cooper, M.A.M.; Blaskovich, M.A.T. Fluorescent Antibiotics: New Research Tools to Fight Antibiotic Resistance. Trends Biotechnol. 2018, 36, 523-536. [CrossRef]

18. Spackman, M.A.; Jayatilaka, D. Hirshfeld surface analysis. CrystEngCom. 2009, 11, 19-32. [CrossRef]

19. Miller, J.; Miller, J.C. Statistics and Chemometrics for Analytical Chemistry, 6th ed.; Pearson Education Limited: London, UK, 2010.

20. Ermer, J.; Miller, J.H.M.B. Method Validation in Pharmaceutical Analysis: A Guide to Best Practice; Wiley-VCH Verlag GmbH\&Co. KGaA: Weinheim, Germany, 2005.

21. Brereton, R.G. Data Analysis for the Laboratory and Chemical Plant; John Wiley \& Sons Ltd.: Hoboken, NJ, USA, 2003. 
22. Validation of Analitical Procedures: Text and Methodology Q2 (R1); International Conference on Harmonisation of Technical Requirements for Registration of Pharmaceutical for Human Use: Geneva, Switzerland, 27 October 1994.

23. Gutow, H.J. Halide $\left(\mathrm{Cl}^{-}\right)$Quenching of Quinine Sulfate Fluorescence: A Time-Resolved Fluorescence Experiment for Physical Chemistry. J. Chem. Educ. 2005, 82, 302. [CrossRef]

24. Najbar, J.; Mac, M. Mechanisms of fluorescence quenching of aromatic molecules by potassium iodide and potassium bromide in methanol-ethanol solutions. J. Chem. Soc. Faraday Trans. 1991, 87, 1523-1529. [CrossRef]

25. Wiśniewski, L.; Deperasińska, I.; Żurowska, B.; Szemijk-Hojniak, A. Effect of solvent polarity on photophysical parameters of 3-aminoflavone. J. Photochem. Photobiol. A Chem. 2011, 224, 62-67. [CrossRef]

26. Bruker. APEX2, SAINT-Plus, XS, XL, XShell; Bruker AXS Inc.: Madison, WI, USA, 2013.

27. Macrae, C.F.; Edgington, P.R.; McCabe, P.; Pidcock, E.; Shields, G.P.; Taylor, R.; Towler, M.; van de Streek, J. Mercury: Visualization and Analysis of Crystal Structures. J. Appl. Cryst. 2006, 39, 453-457. [CrossRef]

28. Groom, C.R.; Allen, F.H. The Cambridge Structural Database in Retrospect and Prospect. Angew. Chem. Int. Ed. 2014, 53, 662-671. [CrossRef]

Sample Availability: Samples of the compound 3-AF are available from the authors. 